\title{
Comparison of geometric and algebraic methods to determine mechanical power in patients with acute respiratory distress syndrome
}

\author{
Bruno Louis ${ }^{1,2}$ and Claude Guérin ${ }^{1,2,3,4,5,6,7^{*}}$ (1)
}

(c) 2019 Springer-Verlag GmbH Germany, part of Springer Nature

\section{Dear Editor,}

The current ventilator-induced lung injury theory implicates inflation work (delivered energy from the ventilator to the respiratory system over each breath) per unit time [1], which is assessed by the mechanical power (MP) [2]. According to the existing literature, the time scale currently selected for MP (inflation energy per unit time) is measured in minutes. According to that convention, MP is the cumulative inflation energy applied over $1 \mathrm{~min}$. The reference method for MP assessment is the geometrical method, which measures the area subtending tidal volume $(\Delta V)$ to airway pressure (Paw) during each insufflation and multiplies this area by respiratory rate $(R R)$ as originally described by Marini et al. [3]. Under a set of assumptions (classical equation of motion, square inspiratory flow), MP can be derived from a complete equation [2] (see electronic supplemental material), which can be simplified as previously described by Gattinoni et al. [2] as follows:

$$
\mathrm{MP}=\mathrm{RR} \times \Delta V \times\left[\frac{\mathrm{PEEP}}{2}-\frac{P_{\text {plat }}}{2}+P_{\text {peak }}\right],
$$

with PEEP as positive end expiratory pressure, $P_{\text {peak }}$ as maximal Paw and $P_{\text {plat }}$ as elastic Paw. This equation can be made easily available at the bedside. Our goal in the present report is to compare the geometrical method and

*Correspondence: claude.querin@chu-lyon.fr

${ }^{3}$ Médecine Intensive Réanimation, Hopital Michalon, 38000 Grenoble, France

Full author information is available at the end of the article the two algebraic methods in patients with acute respiratory distress syndrome (ARDS).

This is a secondary analysis of 34 ARDS patients receiving mechanical ventilation in volume-controlled mode previously reported [4]. Patients' next of kin gave agreement for research. From the records of Paw and flow over time, the reference geometrical MP was measured. From the same breaths, both complete and simplified equations were computed. On each breath, compliance, resistance, total PEEP and $P_{\text {plat }}$ were obtained by the least square regression method and $P_{\text {peak }}$ was directly measured. The investigation was done in patients in the supine position $0^{\circ}$ and repeated in the prone position $0^{\circ}$. Comparisons between methods were performed by Bland and Altman representation, which provided bias and limits of agreement, and by computing the absolute error between methods (common mean divided by bias $\times 100$ ).

There were 7429 breaths analyzed in supine position and 7892 breaths in prone position in the 34 patients. The bias (limits of agreement) were $-2.5 \mathrm{~J} / \mathrm{min} \quad(-4.9$; $-0.1)$ between the simplified equation and the reference in supine position and $-2.8 \mathrm{~J} / \mathrm{min}(-5.9 ;+0.3)$ in prone position, $-1.9 \mathrm{~J} / \mathrm{min}(-4.4 ;+0.5)$ between the complete equation and reference in supine position and $-2.1 \mathrm{~J} /$ $\min (-4.6 ;+0.4)$ in prone position, and $-0.5 \mathrm{~J} / \mathrm{min}$ $(-3.9 ;+2.8)$ between simplified and complete equations in supine position and $-0.7 \mathrm{~J} / \mathrm{min}(-3.3 ;+4.3)$ in prone position (Fig. 1). The median (95\% confidence intervals) absolute error was $8.3 \%(8.2-8.4 \%)$ between the simplified equation and reference and $8.6 \%$ (8.5-8.7\%) in supine and prone positions, respectively. The corresponding values were $3.9 \%(3.0-4.0 \%)$ and $4.5 \%$ (4.4-4.6\%) between 


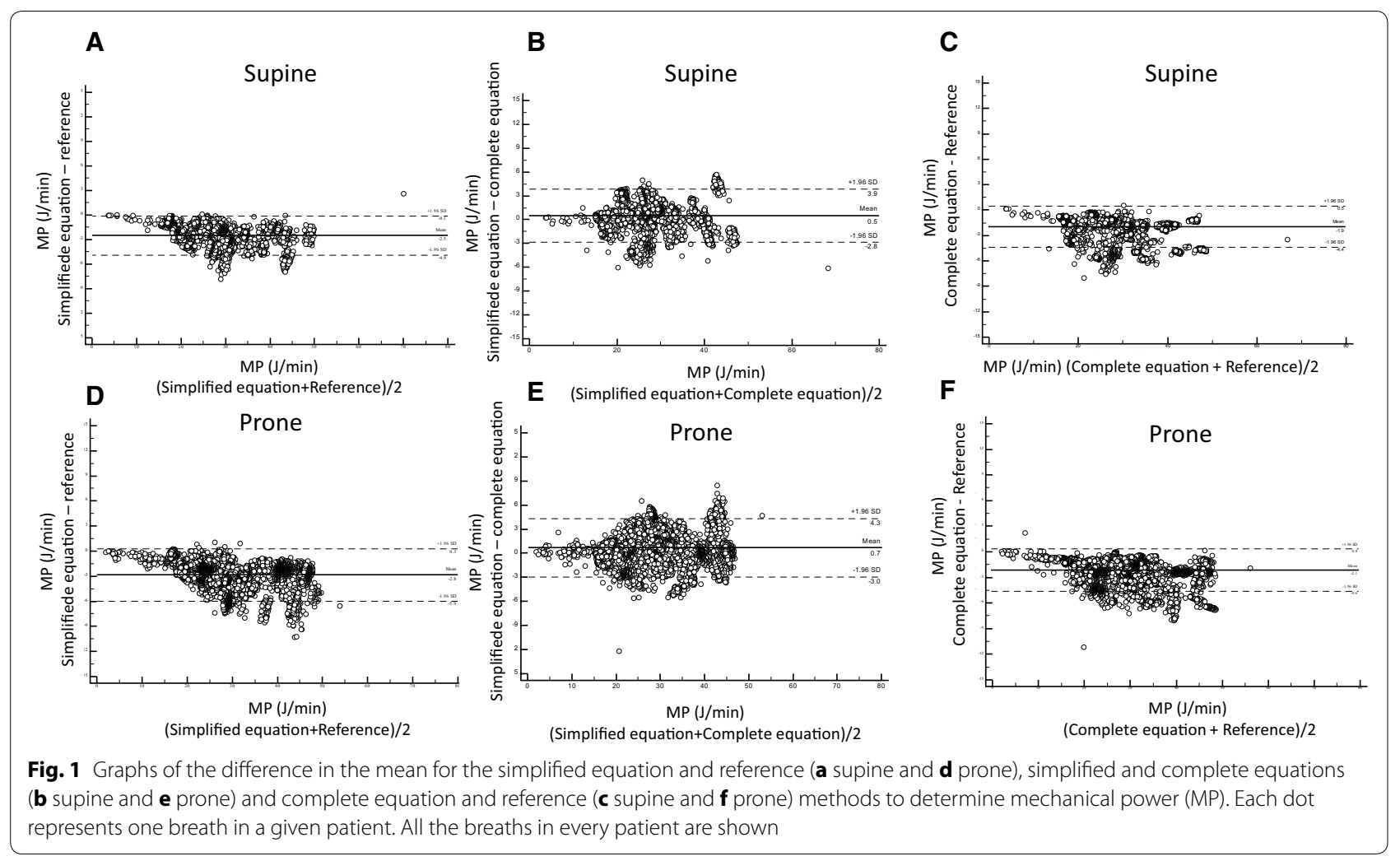

simplified and complete equations, and 5.8\% (5.7-5.9\%) and $5.7 \%(5.7-5.8 \%)$ between complete and simplified equations.

We found a good agreement between simplified and reference methods in each position. There were slight and subtle differences between methods, which can be explained as follows. The geometric method measures the real phenomenon. The complete equation assumes constant flow during the whole insufflation and perfect resistance-elastance behavior for the respiratory system, which may not be true. Compliance and resistance were computed from the least square regression method and, hence, their slight changes during inflation are not taken into account. PEEP total and $P_{\text {plat }}$ were computed from the least square regression method. Total PEEP values, not PEEP values, were used in our calculations. All of these factors may contribute to the differences between methods found in the present study. Overall, the algebraic methods underestimated the reference geometrical MP. The absolute errors were, however, less than $10 \%$ in every instance. $P_{\text {peak }}$ and $P_{\text {plat }}$ must be available for an accurate simplified equation. In patients receiving pressure-controlled ventilation, the set pressure is usually used as the $P_{\text {plat. }}$. However, with this mode, $P_{\text {peak }}$ and $P_{\text {plat }}$ may be different due to resistive pressure drop. In this case, end-inspiratory flow is greater than zero. $P_{\text {plat }}$ should be obtained by performing end-inspiratory occlusion or by extrapolating its value to zero flow. The same is true for volume-controlled mode. However, with the latter, a short end-inspiratory pause allows a clear distinction between $P_{\text {peak }}$ and $P_{\text {plat. }}$. Finally, our study did not intend to compare MP in supine and prone positions.

In conclusion, the simplified equation can be used as an accurate method to compute MP.

\section{Electronic supplementary material}

The online version of this article (https://doi.org/10.1007/s00134-019-05521-4) contains supplementary material, which is available to authorized users.

\section{Author details \\ ${ }^{1}$ Institut Mondor de Recherche Biomédicale INSERM 955, Créteil, France. ${ }^{2}$ CNRS ERL 7000, Créteil, France. ${ }^{3}$ Médecine Intensive Réanimation, Hopital Michalon, 38000 Grenoble, France. ${ }^{4}$ Université de Grenoble, Grenoble, France. ${ }^{5}$ HP2, INSERM 1042, Grenoble, France. ${ }^{6}$ Hospices Civils de Lyon, Lyon, France. 7 Université de Lyon, Lyon, France.}

\section{Compliance with ethical standards}

Conflicts of interest

The authors declare no conflict of interest.

\section{Publisher's Note}

Springer Nature remains neutral with regard to jurisdictional claims in published maps and institutional affiliations. 
Accepted: 4 January 2019

Published online: 16 January 2019

\section{References}

1. Cressoni M, Gotti M, Chiurazzi C, Massari D, Algieri I, Amini M, Cammaroto A, Brioni M, Montaruli C, Nikolla K, Guanziroli M, Dondossola D, Gatti S, Valerio V, Vergani GL, Pugni P, Cadringher P, Gagliano N, Gattinoni L (2016) Mechanical power and development of ventilator-induced lung injury. Anesthesiology 124:1100-1108
2. Gattinoni L, Tonetti T, Cressoni M, Cadringher P, Herrmann P, Moerer $\mathrm{O}$, Protti A, Gotti M, Chiurazzi C, Carlesso E, Chiumello D, Quintel M (2016) Ventilator-related causes of lung injury: the mechanical power. Intensive Care Med 42:1567-1575

3. Marini JJ, Rodriguez RM, Lamb V (1986) Bedside estimation of the inspiratory work of breathing during mechanical ventilation. Chest 89:56-63

4. Riad Z, Mezidi M, Subtil F, Louis B, Guerin C (2018) Short-term effects of the prone positioning maneuver on lung and chest wall mechanics in patients with acute respiratory distress syndrome. Am J Respir Crit Care Med 197:1355-1358 